\title{
Effect of natural inhibitors on microalloyed steel corrosion in E5 and E10 biofuels
}

\author{
I.Vasquez-Aguirre ${ }^{1}$, A. Torres-Islas ${ }^{1, *}$, M.G. Valladares-Cisneros ${ }^{1}$, J. Colin $^{1}$ and H. Martinez $^{2}$ \\ ${ }^{1}$ Facultad de Ciencias Químicas e Ingeniería , Universidad Autónoma del Estado de Morelos, Av. \\ Universidad 1001, Col. Chamilpa, C.P. 62209, Cuernavaca, Morelos, México. \\ ${ }^{2}$ Laboratorio de Espectroscopia, Instituto de Ciencias Físicas, Universidad Nacional Autónoma de \\ México, A.P. 48-3, C.P. \&2210, Cuernavaca - 62210, Morelos México. \\ "E-mail: alvaro.torres@uaem.mx
}

Received: 3 September 2021 / Accepted: 21 October 2021 / Published: 6 December 2021

In this study, two natural extracts were evaluated as corrosion inhibitors, O. Vulgare and M. Spicata, in sugar cane ethanol mixed with gasoline (E5 and E10 biofuels), which were in contact with X-70 microalloyed steel with different heat treatments. The electrochemical techniques used were potentiodynamic polarization and electrochemical impedance spectroscopy, and $\mathrm{I}_{\text {corr }}$ was used as an indicator of the corrosion level. The results indicated that the main corrosion mechanism under all conditions is continuous anodic dissolution, which results from concentration polarization. Also, it was found that the microstructure of steel plays a determining role in the inhibition mechanism, which is influenced by energetic reactions related to the Temkin isotherm and physisorption.

Keywords: Natural inhibitors, Biofuels, X-70 microalloyed steel, Corrosion resistance.

\section{FULL TEXT}

(C) 2022 The Authors. Published by ESG (www.electrochemsci.org). This article is an open access article distributed under the terms and conditions of the Creative Commons Attribution license (http://creativecommons.org/licenses/by/4.0/). 